\title{
A cidadania na perspectiva de Raquel Paiva: defesas em torno das comunidades, da comunicação comunitária e da mobilidade urbana ${ }^{1}$
}

\author{
The citizenship at Raquel Paiva's perspective: defenses around \\ communities, community communication and urban mobility \\ Mayara Jordana Sousa Santana ${ }^{2}$ \\ (mayarajordana@gmail.com) \\ Simone Antoniaci Tuzzo ${ }^{3}$ \\ (simonetuzzo@hotmail.com)
}

\section{Resumo}

A amplitude na definição do conceito de cidadania permite a delimitação do tema por meio de recortes que privilegiem perspectivas associadas tanto ao exercício de direitos e deveres, como em abordagens feitas por diversos autores. Neste artigo, o objetivo é discorrer, teoricamente, sobre os conceitos relacionados à cidadania presentes nas obras de Raquel Paiva, promovendo um diálogo entre teóricos que corroboram e refutam as ideias da autora. Ao longo do texto, a cidadania será a tese da argumentação de Raquel Paiva ao defender que há discrepâncias na garantia de direitos entre elites e minorias. Desse modo, na fundamentação do artigo, serão apresentados conceitos como: a formação e as especificidades entre comunidade e sociedade, minorias e movimentos sociais. A mídia e sua associação com a cidadania também se faz presente no estudo, tese essa encontrada nas obras de Raquel Paiva, especialmente, ao explicar e defender a comunicação comunitária como uma forma de conceder voz aos excluídos social e politicamente. Ainda na mais recente linha de pesquisa de Raquel Paiva, encontram-se defesas em torno da mobilidade, que será tratada como uma nova maneira de apreender os espaços urbanos nas cidades, onde ocorre a cidadania.

Palavras-chave: Cidadania. Comunidades. Comunicação comunitária. Mobilidade urbana.

\begin{abstract}
The amplitude in the definition about the concept of citizenship allows the delimitation of the theme by clipping issues which make privilege of the perspectives associated as in the exercise of both rights and duties in the approaches made by several authors. In this article, the goal is expatiate, theoretically, about the concepts related to the citizenship as defined at Raquel Paiva's literature, promoting a dialogue between theoreticians who corroborate and refute her ideas. Over the text, the
\end{abstract}

\footnotetext{
${ }^{1}$ Este trabalho foi desenvolvido dentro do Projeto de Pesquisa Rupturas Metodológicas para uma leitura crítica da Mídia entre os Programas de Pós-Graduação da UFG e UFRJ, que integra a ação transversal nº 06/2011 Casadinho/Procad.

${ }^{2}$ Mayara Jordana Sousa Santana é aluna especial do Programa de Pós-Graduação - Mestrado em Comunicação - pela Faculdade de Comunicação e Biblioteconomia - FACOMB da Universidade Federal de Goiás- UFG (2013); especialista em Assessoria de Comunicação e Marketing pela UFG (2012) e graduada em Comunicação Social - habilitação Jornalismo pela UFG (2008). Jornalista no Instituto Federal de Educação, Ciência e Tecnologia de Goiás - IFG, Câmpus Goiânia.

${ }^{3}$ Simone Antoniaci Tuzzo é Doutora em Comunicação pela UFRJ, Mestre e Graduada em Comunicação pela UMESP, Coordenadora do Projeto de Pesquisa Rupturas Metodológicas para uma leitura crítica da Mídia entre os Programas de Pós-Graduação da UFG e UFRJ, que integra a ação transversal no 06/2011 - Casadinho/Procad. Professora e Orientadora do Trabalho desenvolvido na Disciplina Seminários Temáticos de Mídia e Cidadania - PPGCOM - UFG.
} 
citizenship will be the thesis of Raquel Paiva's argumentation to defend that discrepancies exist in the guarantee of rights between elites and minorities. Thus, in the foundation of this article will be presented concepts like: the foundation and the specificities between community and society, minorities and social movements. The media and its association with the citizenship are also presented in this article, based on Raquel Paiva's literature, specially to explain and defend the community communication as a way to grant voice to those who are socially and politically excluded. In the most recent research of Raquel Paiva, defenses around mobility are founded, which will be considered as a new way to apprehend the urban spaces in the cities, where the citizenship occur.

Keywords: Citizenship. Communities.Community Communication. Urban Mobility.

\section{Introdução}

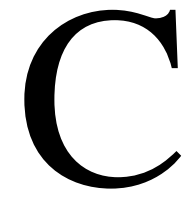

idadania - para sociedades de regimes político-democráticos- apresenta-se como algo posto, irrefutável, acessível a todos, como direitos e deveres garantidos universalmente. Isso, no entanto, constata-se na perspectiva daqueles que gozam de suas benesses em sociedade. Em outra abordagem, nas obras da autora Raquel Paiva, o leitor é levado a afastar-se de seu lugar de conforto em relação à cidadania e olhar para grupos marginalizados nesse processo de se reconhecerem e serem reconhecidos enquanto cidadãos.

Professora associada da Escola da Comunicação - ECO da Universidade Federal do Rio de Janeiro-UFRJ; Doutora em Comunicação pela UFRJ; Mestre em Comunicação pela UFRJ; Jornalista; atual Diretora Científica da Sociedade Brasileira de Estudos Interdisciplinares da Comunicação - Intercom; Pesquisadora; Autora de diversos livros e trabalhos científicos publicados nacional e internacionalmente; e esposa do também renomado autor Muniz Sodré, Raquel Paiva promove um sentimento de alteridade em relação à construção da cidadania, fundamentado no pensamento da Teoria Crítica. Por meio da construção sociológica e teórica sobre comunidade e sociedade, a autora envereda pelo caminho de explicar os processos que levam à exclusão social e a formação de minorias.

Em sua primeira obra: O Espírito Comum: Comunidade, Mídia e Globalismo (1998), Raquel Paiva proporciona um extenso embasamento teórico, para explicar a formação das comunidades e da sociedade, por meio dos conhecimentos da Sociologia, da Antropologia e da Psicologia. A autora defende, em sua obra, a argumentação sociológica. Desse modo, as diferenças entre comunidade e sociedade são introduzidas pela autora, pois são bases para a compreensão dos processos que 
conduziram as sociedades ao individualismo, que, consequentemente, levou à exclusão de diretos e à formação de minoriais.

\section{A Formação das comunidades e das sociedades}

As comunidades são as entidades pioneiras na formação das sociedades. Nas comunidades, são valorizadas determinadas características que são importantes para o agrupamento dos indivíduos, como: identidade coesa, consenso, laços afetivos, localidade geográfica, sentimentos ético e moral alicerçados no tripé - família, igreja e líder de opinião. Já nas sociedades, com o estabelecimento de estruturas legais e burocráticas normatizadoras de condutas, outros valores são capazes de agregar os indivíduos, como: normas generalizantes, individualismo, identificações, diversidade de grupos, caráter global, relações mediadas pela economia, etc.

Compreender essas diferenciações, como propõe Raquel Paiva, não estigmatiza os modelos sociais vigentes em "caixas segmentadoras" ou impossibilita que comunidades e sociedades coexistam, porém, isso permite a delimitação dos valores que são estabelecidos nas relações sociais, os quais proporcionam a consolidação de um agrupamento de indivíduos que passam a ser reconhecidos enquanto cidadãos. Anteriormente a Raquel Paiva, os autores e sociólogos Emile Durkheim e Max Weber discorreram, pioneiramente, a respeito dos valores fundantes de uma coesão social entre os indivíduos, o que proporcionou a formação de sociedades.

Emile Durkheim (2002) dá um tratamento científico à moral, definindo-a como um sistema de regras de valor simbólico que é base das comunidades. $\mathrm{O}$ autor atribui à moral a capacidade de garantir uma coesão entre os indivíduos ao preservar a importância dos interesses coletivos em detrimento dos individuais. Emile Durkheim elaborou ainda o conceito de solidariedade social, responsável pela coesão entre os membros dos grupos, podendo ser expressa por meio de códigos, leis ou regras inconscientes, que são adotados por meio de condutas. Em sua teoria, as regras morais, nas comunidades, "possuem uma autoridade que implica a noção de dever e, em segundo lugar, aparecem-nos como desejáveis, embora seu cumprimento se dê com um esforço que nos arrasta para fora de nós mesmos [...]" (QUINTANEIRO, 2002, p.75).

Segundo o autor, possuímos duas consciências: "Uma é comum com todo o nosso grupo e, por conseguinte, não representa a nós mesmos, mas a sociedade agindo e vivendo em nós. A outra, ao contrário, só nos representa no que temos de pessoal e distinto, nisso é que faz de nós um indivíduo". (DURKHEIM, De la división del trabajo social, p.113, apud QUINTANEIRO, 2002, p. 77). 
Em Max Weber (2002), outro importante conceito que se refere à formação das comunidades e da sociedade é a ação, entendida como toda a conduta humana dotada de uma interpretação subjetiva concedida por quem a executa e também por aquele que a recebe. $\mathrm{O}$ indivíduo, ao orientar essa ação a outros ou a um aglomerado de indivíduos indeterminados e/ou desconhecidos, essa ação passa a ser denominada como social; e o seu agente, como um ser social. Atuação essa que é fundamental para compreender o trabalho feito pelos movimentos sociais.

A partir dessa fundamentação teórica sobre comunidades e sociedade, Raquel Paiva demonstra que, na contemporaneidade, a comunidade tradicional e suas estruturas não são mais compatíveis com a lógica da sociedade de consumo, o que implica no predomínio do individualismo e na exclusão de grupos que não possuem mais uma identidade coesa. Bauman é ainda mais radical ao comparar a tradicional comunidade a uma fortaleza sitiada, "bombardeada por inimigos (muitas vezes invisíveis) de fora e frequentemente assolada pela discórdia interna." (BAUMAN, 2003, p. 19).

Com ponto de vista discordante em relação à Raquel Paiva, Zygmunt Bauman promove em sua obra Comunidade: A Busca por Segurança no Mundo Atual (2003) uma reflexão crítica em relação às comunidades. $\mathrm{O}$ autor defende que a comunidade é um instituto em crise, submetido ao enfraquecimento de seus laços duradouros, em nome da libertação do indivíduo. Ele discorre também a respeito da diminuição dos poderes da comunidade em atribuir papéis generalizantes aos indivíduos pertencentes a agrupamentos.

Bauman imputa a crise das comunidades à modernidade e à diminuição das fronteiras. Especialmente, o autor considera os meios de transportes como um dos principais provocadores dessa crise, porque o surgimento desses veículos tornou difícil o controle das informações que vêm de fora para dentro das comunidades.

O autor defende que, apesar da crise das comunidades, os indivíduos, na pós-modernidade, ainda têm a necessidade de passarem por experiências de pertencimento a um grupo. Surgem então, segundo Bauman, as comunidades estéticas, que são agrupamentos característicos dessa sociedade cujas relações são mediadas pelo consumo, com natureza superficial e de laços transitórios. Nelas, não há exigências de responsabilidades éticas e nem compromissos de longo prazo (BAUMAN, 2003, p.67). Nessas comunidades estéticas, que são sintonizadas com o pensamento individualista, os tradicionais líderes de opinião são substituídos por duas autoridades. 
Em nossos tempos, depois da desvalorização das opiniões locais e do lento mas constante desaparecimento dos "líderes locais de opinião" (problema que discuti de modo mais completo nos dois primeiros capítulos de Globalização: As consequências humanas) restam duas autoridades, e só duas, capazes de conferir segurança aos juízos que pronunciam ou manifestam em suas ações: a autoridade dos expertos, pessoas "que sabem" (cuja área de competência é excessivamente ampla para ser explorada e testada pelos leigos), e a autoridade do número (na suposição de que quanto maior o número menor a chance de que estejam errados). A natureza da primeira autoridade faz dos extraterritoriais da Risikogesselschaft um mercado natural para a "explosão do aconselhamento". A natureza da segunda os leva a sonhar com a comunidade e dá forma à comunidade de seus sonhos.

Essa comunidade dos sonhos é uma extrapolação das lutas pela identidade que povoam suas vidas. É uma "comunidade" de semelhantes na mente e no comportamento; uma comunidade do mesmo — que, quando projetada na tela da conduta amplamente replicada/copiada, parece dotar a identidade individualmente escolhida de fundamentos sólidos que as pessoas que escolhem de outra maneira não acreditariam que possuíssem. Quando monotonamente reiteradas pelas pessoas em volta, as escolhas perdem muito de suas idiossincrasias e deixam de parecer aleatórias, duvidosas ou arriscadas: a tranquiilizadora solidez de que sentiriam falta se fossem os únicos a escolher é fornecida pelo peso impositivo da massa. (BAUMAN, 2003, p. 60-61).

Mesmo na obra de Bauman, ao repudiar as tradicionais comunidades, o autor as reconhece como um "elo perdido", que ainda é buscado pelos indivíduos, mesmo por aqueles que compõem uma parcela mínima dos cosmopolitas de status extraterritorial. São as comunidades as instituições capazes de conferir uma mínima segurança em uma sociedade caracterizada, por Bauman, como "líquido-moderna", ou seja, em que aquilo que é durável e estável nas relações modifica-se, evapora-se, para o revigoramento das condutas.

Por mais que prezem sua autonomia individual, e por mais confiança que tenham em sua capacidade pessoal e privada de defendê-la com eficiência e dela fazer bom uso, os membros da elite global por vezes sentem necessidade de fazer parte de alguma coisa. Saber que não estamos sós e que nossas aspirações pessoais são compartilhadas por outros pode conferir segurança (BAUMAN, 2003, p.60).

Muniz Sodré (2005) também corrobora com a ideia de enfraquecimento das comunidades tradicionais. Para Sodré, as relações sociais são mediadas pelo paradigma do mercado, e não mais pelos valores morais, éticos e estéticos. Com o surgimento dos diversos meios de transportes, de veículos de comunicação e graças à valorização da informação nas sociedades, as relações entre os sujeitos, na contemporaneidade, passam a ser mediadas, principalmente, pelos interesses e normas do mercado, deixando de serem relevantes alguns elementos que, anteriormente na fase industrial, 
reuniam os indivíduos em grupos coesos, como: trabalho, igreja, sindicatos, família e etc. Muniz Sodré (2013) define a sigla SIG (Simultaneidade, Instantaneidade e Globalidade) como o novo tripé orientador dos agrupamentos sociais nas sociedades atuais.

Raquel Paiva amplia esse pensamento de Muniz Sodré e discorre que, a partir do momento, em que a comunidade tradicional torna-se incapaz de agregar os indivíduos, por meio do lazer, da profissão e da religião, as identificações grupais são mais procuradas, reconhecidas e aceitas em detrimento de uma identidade única e coesa, a qual não é mais de capaz de agrupar os indivíduos nas sociedades contemporâneas. "Em seu lugar ergue-se uma diversidade de grupos que o indivíduo frequenta, participa, descentralizando seus múltiplos interesses.” (PAIVA, 1998, p.18). Logo, o aumento do individualismo em sociedade e a marginalização de interesses e de indivíduosmovimentação essa que é orientada por esse modus operandi SIG, definido por Muniz Sodré proporcionam uma reflexão crítica sobre a cidadania para as minorias excluídas desse processo.

\section{A cidadania presente nas posturas grupais}

A cidadania, segundo Raquel Paiva e Muniz Sodré, é percebida pelas contradições sociais que são notadas, por meio de uma visão crítica em relação à desigualdade social e pela negação das instituições tradicionais (família, igreja, partido), como mediadoras dos interesses coletivos. Estabelecem-se, então, as minorias, que representam uma parcela da sociedade impossibilitada de falar e de ser ouvida social e politicamente.

Nesse cenário de segregacionismo social, Muniz Sodré (2005) coloca um ponto importante que conduziu as minorias a abraçarem lutas assumidas enquanto questões sociais, como: o rompimento entre o espaço público e o espaço político. De acordo com o autor, a diminuição do poder e da interferência do Estado, no regime neoliberal, e a expansão do mercado e seus valores foram fatores que levaram à diminuição da esfera político-social, onde se dá a cidadania.

As ações sociais das minorias são motivadas pela busca de interesses comuns e, especialmente, pelo comprometimento em obter o papel de cidadãs, o qual lhes foi negado, além do desejo de interferir nas decisões do poder público. É nesse contexto que se destaca a atuação dos movimentos sociais.

No Brasil, recorda Raquel Paiva, os anos de 1970 e 1980 foram os principais períodos de efervescência dos movimentos sociais motivada pelo fim do regime militar (1964-1985) e pela redemocratização política. Nessa mesma linha de discussão sobre a cidadania nos movimentos 
sociais, a autora Cicilia Peruzzo (1998) - contemporânea de Raquel Paiva - concebe os movimentos sociais enquanto manifestações das classes populares. Em sua obra, Comunicação nos movimentos populares: a participação na construção da cidadania, Cicilia Peruzzo apresenta um panorama histórico das lutas promovidas pelos movimentos sociais e os tipos de movimentos.

Outra autora que também define os movimentos sociais é Maria da Glória Gohn (2003), concebendo-os como, "ações sociais coletivas de caráter sociopolítico e cultural que viabilizam distintas formas da população se organizar e expressar suas demandas.” (GOHN, 2003, p.13). Segundo Maria da Glória Gohn, os movimentos sociais exercitam, principalmente, o que Habermas denominou como o agir comunicativo, por meio da atuação em redes sociais locais, regionais, nacionais ou internacionais e também por se utilizarem dos novos meios de comunicação e de informações, para terem voz e serem ouvidos.

A ideia que é compartilhada entre essas três autoras é o reconhecimento de que o ambiente midiático passa a definir, de maneira decisiva, a atuação dos movimentos sociais, especialmente, devido à falha do Estado em garantir direitos cidadãos às minorias e também na incapacidade do Estado em representá-los. Raquel Paiva defende uma nova forma de organização dos movimentos sociais: as minorias flutuantes. Tratam-se, de acordo com a autora, de grupos minoritários que agem em sintonia com o ambiente midiático, produzindo formas de atuação, em que o objetivo é, frequentemente, o aparecimento na mídia (PAIVA, 2005, p17).

Dessa maneira, alguns movimentos podem tanto possuir uma militância organizacional e partidária ativa, como estrutura de um movimento social, como, ao mesmo tempo, conseguir viver ao sabor de acontecimentos, "flutuando ativamente" por entre os assuntos do cotidiano. Comporta, por essa razão, uma forma de movimento que pode ser definida por "minorias passionais", capazes de comprometer a governabilidade democrática, e sua presença caracteriza definitivamente o perfil dos movimentos atuais no momento em que vigora a "era das turbulências." (PAIVA, 2005, p.18).

As mudanças provocadas nos movimentos sociais, dos pioneiros até os do século XXI, não afetaram um valor primordial presente nesses movimentos, que é a participação cidadã. Nas obras das autoras mencionadas anteriormente, nota-se que o agir dos movimentos sociais - mesmo daqueles que são dependentes da mídia- pauta-se pela atuação de sujeitos ativos, que buscam apontar e construir propostas ou políticas públicas para uma nova realidade social, e não esperam programas elaborados "de cima para baixo", sem a participação dos cidadãos. 
Nesse contexto, Raquel Paiva considera que é incompatível o retorno da visão romanceada de luta contra hegemônica, por parte dos movimentos sociais, e nem a mediação tradicional feita pelas comunidades. A autora coloca que, no panorama atual de busca por uma cidadania ampla, novos conceitos passam a inter-relacionar-se com os movimentos sociais e precisam entrar na agenda da sociedade civil organizada, como: aceitação, convivialidade, diferença/igualdade, inclusão, compartilhamento, pertencimento, diálogo, comunicação (PAIVA, 2005, p.23).

Esse último conceito - comunicação - ganha lugar de destaque nos movimentos sociais, especialmente, por passar à competência da mídia a tarefa de proporcionar um sentimento de espaço público, permitindo a circulação de opiniões contraditórias em sociedade.

\section{Mídia, cidadania e comunicação comunitária}

O espaço público, de maneira simbólica, passa ser uma "ágora" da mídia, termo esse que se refere à pioneira democracia presente na polis grega, onde os indivíduos reconhecidos como cidadãos tomavam conhecimento das decisões políticas, no século VIII, e era o local símbolo da esfera pública. Porém, a ágora midiática tem suas limitações na contemporaneidade, pois os elementos fundantes da mídia perpassam pela lógica do mercado, e não pela máxima dos interesses coletivos.

Desse modo, o dever de promover uma cidadania no espaço midiático fundamenta-se na espetacularização e na reprodução de estereótipos, de acordo com Raquel Paiva, atendendo a transmissão de informações, segundo os princípios da comunicação de massa. Comunicação essa que atua em um grupo composto por um grande número de pessoas anônimas, heterogêneas, atomizadas, que estão social e geograficamente dispersas.

Raquel Paiva atribui ao jornalismo a responsabilidade de promover o espaço público na mídia, porém, com limitações, pois a lógica do jornalismo, explica a autora, é a compulsão pela velocidade e pelo espetáculo. "É entristecedor constatar que o jornalismo atual não repara no que produz. [...] O jornalismo deveria estar para além, muito além de ser espaço de reprodução de valores segregacionistas." (PAIVA, 2002, p.37, 39).

O jornalismo, portanto, não sendo capaz de promover uma mediação cidadã que englobe a diversidade de interesses dos grupos, colabora para a busca de uma outra alternativa de mediação, que encontra refúgio na comunicação comunitária, também denominada comunicação popular, que é feita pelos movimentos sociais. Raquel Paiva explica que esse tipo de comunicação é orientada, 
principalmente, por determinações grupais ou comunais, e não prioritariamente pelo sistema empresarial que visa ao lucro.

Segundo a autora, na comunicação comunitária, são mais valorizados os objetivos e o comprometimento entre as partes para se alcançar as metas programadas que o uso do mais moderno sistema de comunicação. Na escolha das mídias para a propagação dos conteúdos na comunicação comunitária são valorizados critérios, como: adequação do veículo ao projeto global, a compreensão das mídias a serem escolhidas, a linguagem a ser adotada e a programação, essas últimas não necessariamente são determinadas pelo saber técnico advindo de profissionais de comunicação (PAIVA, 1998, p. 47).

A estrutura comunicacional de um veículo de comunicação inscrito na ordem comunitária segue padrões distintos dos veículos existentes, e ao mesmo tempo em que são alteradas as bases responsáveis pela articulação discursiva. A histeria mediática está ausente da mensagem produzida na comunicação comunitária, pois o que é dito ali possui efeito direto sobre a vida das pessoas, não tem nenhuma semelhança como o fenômeno do falatório, característico da estrutura histérica (PAIVA, 1998, p. 56).

Outras autoras também discorrem sobre comunicação comunitária dialogando com Raquel Paiva, como: Maria da Glória Gohn (2003) e Cicilia Peruzzo (1998). Essa última defende a participação popular na comunicação, como um elemento significativo na ampliação da cidadania, principalmente, por se tratar de uma das maneiras de se realizar a cidadania participativa.

Comunicação popular, enfim, contribui para a democratização da sociedade e a conquista da cidadania. Que não significa só alguém poder votar a cada cinco anos naqueles que vão decidir por ele, mas também aprender a participar politicamente da leitura do bairro e da escola para os filhos, a apresentar sua canção e seu desejo de mudança, a denunciar condições indignas, a exigir seus direitos de usufruir da riqueza gerada por todos, por meio de melhores benefícios sociais e de salários mais justos, a organizar-se e a trabalhar coletivamente. A comunicação popular não faz tudo isso por si só, mas apenas se estiver inserida na dinâmica dos movimentos, gerando-se a partir deles, e, como consequência, caminhando na mesma direção por eles apontada (PERUZZO, 1998, p. 158).

A comunicação comunitária, mesmo podendo utilizar das mesmas mídias presentes nos grandes veículos de comunicação, não se coloca como uma força capaz de superar os meios de comunicação de massa, explica Peruzzo (1998, p. 130). Tanto a comunicação de massa quanto a comunicação comunitária complementam-se em suas divergências; essa, por não ser homogênea, mas pluralista e histórica, e aquela, por servir ao campo do divertimento e da informação. 
Entre alguns exemplos de forma de comunicação a serviço das comunidades na América Latina, a autora Cicilia Peruzzo (1998) cita os alto-falantes, que atuam como "rádios do povo", conforme três modelos: um, em que os alto-falantes são administrados, voluntária e coletivamente como veículos de comunicação, com uma programação baseada em informação, entretenimento ou utilidade pública; o segundo modelo é administrado da mesma maneira que o primeiro, porém é dirigido por apenas uma ou duas pessoas, tomadas como amantes do rádio; e, por fim, o terceiro modelo que se coloca como um veículo a serviço da comunidade, mas serve a interesses de particulares que almejam o reconhecimento público, prestígio e emprego em grandes emissoras, podendo veicular anúncios e angariar outras formas de patrocínio.

Outras experiências de comunicação comunitária, na América Latina, citadas por Cicilia Peruzzo, são as emissoras radiofônicas, como: Rádios mineiras bolivianas; Rádio Dominicana "Rádio Enriquillo", além das rádios revolucionárias, rádios guerrilheiras e rádios livres. Rádios essas que são distintas em suas motivações, circunstâncias, estratégias, gestão e conteúdos, mas guardam fatores em comum - excetuando-se as rádios revolucionárias - "o fato de não se enquadrarem na estrutura oficial dos meios de comunicação de massa, de não operarem no circuito de ondas controlado pelas organizações estatais.” (PERUZZO, 1998, p. 215).

Mesmo com o advento da comunicação comunitária promovida pelos movimentos sociais, o agir da sociedade civil organizada é capaz de captar a atenção das mídias massivas e terem algumas de suas demandas sociais inclusas no agendamento midiático. Maria da Glória Gohn (2003, p.1617) sistematiza quatro pontos em que os movimentos sociais estão retornando à mídia neste milênio: As lutas em defesa das culturas locais, contra os devastadores da globalização; Reivindicações por ética na política e, ao mesmo tempo, vigilância sobre a atuação estatal/governamental; cobertura de áreas referentes às subjetividades das pessoas em relação às questões, como: sexualidade, crenças, valores; e, por fim, busca por autonomia nos movimentos sociais que desenvolvem projetos e pensam os grupos envolvidos, estabelecendo parcerias, seja com a iniciativa privada ou com órgãos públicos.

\section{Espaços públicos nas cidades contemporâneas}

Recentemente, a autora Raquel Paiva tem orientado as discussões sobre cidadania na perspectiva da mobilidade urbana, como foi exposto na palestra Expressões do comum na cidade- 
Mídia locativa, a ocupação pela mobilidade política, estrangeiros (2013), realizada na Universidade Federal de Goiás (UFG) e na Universidade Federal do Rio de Janeiro (UFRJ). ${ }^{4}$

Declaradamente favorável à adoção do uso de bicicletas como uma nova maneira de apreensão dos espaços públicos nas cidades, a autora defende a perspectiva de uma falência no modelo de mobilidade urbana, porque, segundo ela, a ideia de deslocamento, presente nas cidades contemporâneas, é excludente. De acordo com a autora, as soluções para as cidades são pensadas para os transeuntes de automóveis. A resolução dos problemas de convívio na sociedade é pensada, segundo Raquel Paiva (2013), por dirigentes que vislumbram, apenas, o aprimoramento do transporte coletivo como uma solução viável para as cidades.

Nesse sentido, Muniz Sodré corrobora com Raquel Paiva ao afirmar, na palestra A cidade comum e as novas formações do comum na cidade (2013), que a urbanização nas cidades contemporâneas resume-se a um aglomerado de indivíduos isolados, supostamente livres e subjugados à lógica econômica, cujas regras primam por transformarem as cidades em um lugar da gestão e da eficácia nos deslocamentos e, consequentemente, nos relacionamentos sociais.

Marshall McLuhan já discorria, em 1962, que além dos meios de transportes, qualquer grande meio de comunicação alteraria toda a perspectiva das pessoas em relação à espacialização, isso porque, os meios de comunicação servem às extensões das faculdades humanas, bem como os meios de transportes. McLuhan contribuiu para o desenvolvimento do conceito de experiência da aldeia global, ao explicar que a "era da eletrônica da cibernetização está unificando e integrando, enquanto a era mecânica foi fragmentadora e dissociadora." (MCLUHAN, 2005, p.78).

Se o exercício e a troca de conhecimentos inexauríveis eleva a qualidade do homem, então na era eletrônica ele terá a sua primeira oportunidade universal de ser ricamente humano. Mas para alguns poderia parecer que a essa extensão do diálogo humano até abarcar todos os homens e todos os tipos de conhecimento converteria o próprio globo num computador único (MCLUHAN, 2005, p. 57).

Já Pierre Lévy afirma que os novos meios de comunicação estabeleceram um espaço invisível de conhecimentos, saberes e potências de pensamento capaz de transformar a cognição das pessoas em sociedade, através de experiências no ciberespaço. Ao mesmo tempo em que esses espaços de convivências foram virtualizados, os laços sociais sofreram impactos.

\footnotetext{
${ }^{4}$ A palestra foi proferida no Seminário Internacional "Comunidade, Mídia e Cidade", no período de 8 a 12 de abril de 2013 como parte das ações realizadas no Projeto "Rupturas Metodológicas para uma Leitura Crítica da Mídia", dentro da Ação Transversal n 06/2011 - Casadinho/Procad, processo número 552283/2011-8.
} 
A evolução da técnica, o progresso da ciência, as turbulências geopolíticas e os elementos aleatórios dos mercados dissolvem os ofícios, pulverizam as comunidades, obrigam as regiões a se transformar, as pessoas a se deslocar, mudar de lugar, de país, de costumes e de língua. A desterritorialização muitas vezes fabrica a exclusão ou rompe os laços sociais. Quase sempre confunde as identidades, pelo menos aquelas que se fundavam sobre pertenças ou "raízes". Resultam em um terrível desajuste, uma imensa necessidade de coletivo, de laço, de reconhecimento e de identidade. Nesse terreno, proliferam racismos, integrismos, nacionalismos e máfias. [...] Em nossa época, as técnicas disponíveis permitem fornecer a todos mais do que é necessário. Somos forçados a concluir que a escassez é doravante socialmente produzida, que a miséria e a exclusão são organizadas, mesmo que não sejam deliberadamente visadas (LÉVY, 2007, p.42-43),

A era da cibernetização se propõe unificadora para as comunidades, outrora desterritorializa; aproxima distâncias e culturas, mas segrega. Essa era põe à margem ou simplesmente não contabiliza aqueles que não têm acesso e nem condições de se inserirem no processo de virtualização.

Muniz Sodré (2001) acredita que a internet não foi capaz de acabar com vínculos sociais presentes na comunidade, mas permitiu às pessoas estarem muito mais conectadas, porém não vinculadas. Para Muniz Sodré (2013), o moderno sujeito da consciência burguesa é o cidadão consumidor. A economia e o impacto da tecnologia servem de matriz para o relacionamento desses cidadãos nas cidades. Nesse mesmo sentido, a cidade, então, para Raquel Paiva (2013), é considerada como um verdadeiro laboratório social, onde a mobilidade não depende somente de transportes, mas da comunicação.

Além das limitações advindas da distância física, a hostilidade social é uma nova maneira de convivência na ecologia urbana. Além do isolamento visível, que é evidente nas delimitações feitas pelos muros, tem-se o isolamento invisível, que determina onde cada tipo de pessoa pode circular nas cidades e ocupar os espaços.

Desse modo, o impacto das novas tecnologias e a predominância de uma era das finanças limitam, a alguns indivíduos, a possibilidade de estarem em vários lugares ao mesmo tempo. A virtualização das relações sociais também é reproduzida nas cidades, por meio de um simulacro de um real de natureza técnico-científica, explica Muniz Sodré (2013). A cidade hoje, para Sodré, é a reprodução de modelos, signos e mensagens que valorizam a eficácia e o bom desempenho técnico, o que redefine os espaços urbanos. E para controlar esse movimento, Muniz Sodré atribui ao marketing a responsabilidade de ser o estimulador e o controlador das organizações sociais, produzindo infinitos desejos e segmentando, simbolicamente, os grupos presentes nas cidades. 
Esse simulacro do real, baseado na gestão da eficácia e da eficiência no deslocamento nas cidades, tem levado ao desinvestimento ou mesmo a destruição dos espaços públicos nas cidades, onde se dava a cidadania, explica Raquel Paiva (2013). Assim, a existência coletiva nos espaços públicos foi diminuída e passou a ocorrer em espaços privados, como os shoppings, onde os “códigos e regras privados e grupais não são mais calcados no consenso geral entre a sociedade, e sim em intepretações de parcialidades" (PAIVA, 2002, p.35).

\section{Considerações Finais}

Infere-se que Raquel Paiva, ao ampliar sua linha de pesquisa para o debate sobre mobilidade urbana e transportes nos seus estudos mais recentes, essa nova fase não significa o abandono das discussões de cidadania e de comunidades realizadas em suas obras anteriores, mas sim uma nova proposta de rediscutir as posturas grupais, o espaço público e a promoção da cidadania. Em suas obras, Raquel Paiva traz para o centro das discussões sobre cidadania questões que envolvem comunidades, sociedades, comunicação comunitária, cidades e mobilidade urbana, com foco nas discrepâncias de direitos entre os cidadãos.

Raquel Paiva enfatiza a modificação do olhar dos cidadãos ao defender o uso das bicicletas nas cidades, como uma nova maneira de possuir os espaços urbanos, diferentemente dessa ideia reguladora que pensa as cidades a partir do predomínio dos automóveis. Ela sugere a inclusão da sensorialidade nos estudos sobre deslocamento, o que, consequentemente, conduzirá a constatação de que a ocupação do espaço nas cidades define o urbano e a nova cidadania.

Da recente linha de pesquisa adotada por Raquel Paiva até a pioneira que trata de comunidades, um fato que é recorrente e que é possível de se deduzir em suas obras é a participação cidadã, ou seja, é a defesa por uma atuação ativa dos indivíduos organizados social e politicamente em prol de interesses daqueles que são considerados como minorias, porque seus direitos não estão sendo privilegiados pelo Estado e prossegue, nas sociedades atuais, a dificuldade das minorias de interferirem nas políticas públicas. Nas obras de Raquel Paiva, infere-se que, sejam nas comunidades, nos movimentos sociais ou nas cidades, a exclusão social de grupos ou de interesses coletivos continua ocorrendo, de maneira visível ou invisível.

Analisar a cidadania na perspectiva de Raquel Paiva é constatar que é preciso tratar os desiguais de forma desigual, para que se alcance a isonomia de direitos em sociedade, reconhecendo que existem limitações na maneira pela qual a cidadania ocorre entre elite e periferia. A proposta de 
adoção do uso de bicicletas como uma solução para a mobilidade urbana, presente na nova linha de pesquisa de Raquel Paiva, sugeri que a autora continua colocando-se em defesa de minorias e propondo alternativas contra hegemônicas para que a cidadania ocorra de maneira plena, assim como procedeu em seus estudos anteriores sobre comunidades e comunicação comunitária.

A atualização dos seus estudos, trazendo a mobilidade para as discussões sobre cidadania, é muito pertinente para o momento atual, porque demonstra que, nessa sociedade da era das finanças, ser cidadão imbrica-se com ser consumidor. Torna-se perceptível que as cidades brasileiras não são mais pensadas, nos seus projetos urbanísticos e nem nas suas políticas de zoneamento ecológicoeconômico, como territórios democráticos e espaços públicos para as comunidades, mas como locais de segregacionismo econômico entre os cidadãos.

Nesse sentido, a mobilidade urbana é uma importante variável para a apreensão do exercício da cidadania, principalmente, naquilo que Raquel Paiva se propõe, que é o de não apenas interpretar o contexto atual para a promoção da cidadania, mas "transformá-lo e inventá-lo, empenhados na construção de novas subjetividades e cidadanias ativas da história.” (PAIVA, 2002, p.40).

Artigo submetido em 20/09/2013 e aceito em 01/10/2013.

\section{Referências}

BAUMAN, Zygmunt. Comunidade: a busca por segurança no mundo atual. Rio de Janeiro: Jorge Zahar Editor Ltda, 2003.

GOHN, Maria da Glória (Org.). Movimentos sociais no século XXI: antigos e novos atores sociais. Petrópolis, RJ: Vozes, 2003.

LÉVY, Pierre. A inteligência coletiva: por uma antropologia do ciberespaço. 5. ed. São Paulo: Loyola, 2007. Disponível em: <http://books.google.com.br/books?hl=pt-BR\&lr=\&id=N9QHkFT_ WC4C\&oi=fnd\&pg=PA11\&dq=Pierre+Levy\&ots=HvUHkj2KR2\&sig=PAsvx0ZNQFY1UIyqfb3NtOZGwI>. Acesso em: 24 maio. 2013.

MCLUHAN, Marshall; MCLUHAN, Sthephanie; STAINES, David (Org.). et al. McLuhan por McLuhan: conferências e entrevistas. Rio de Janeiro: Ediouro, 2005.

PAIVA, Raquel; HAJJI, Mohamed. Expressões do comum na cidade - Mídia locativa, a ocupação pela mobilidade, política, estrangeiros. In: SEMINÁRIO COMUNIDADE, MÍDIA E CIDADANIA - UFG/UFRJ,1., Goiânia, 2013.

PAIVA, Raquel. O espírito comum: comunidade, mídia e globalismo. Petrópolis, RJ: Vozes, 1998. 
PAIVA, Raquel. A publicização da ética no espaço midiatizado. In: PAIVA, Raquel (Org.). Ética, cidadania e imprensa. Rio de Janeiro: Mauad, 2002.

PAIVA, Raquel. Mídia e política de minorias. In: PAIVA, Raquel; BARBALHO, Alexandre (Orgs.). Comunicação e cultura das minorias. São Paulo: Paulus, 2005.

QUINTANEIRO, Tania; BARBOSA, Maria Ligia de Oliveira; OLIVEIRA, Márcia Gardênia. Um toque de clássicos: Marx, Durkheim e Weber. 2. ed. Belo Horizonte: Editora UFMG, 2002.

SODRÉ, Muniz. Por um conceito de minoria. In: PAIVA, Raquel; BARBALHO, Alexandre (Orgs.). Comunicação e cultura das minorias. São Paulo: Paulus, 2005.

SODRÉ, Muniz. A cidade comum e as novas formações do comum na cidade. In: SEMINÁRIO COMUNIDADE, MÍDIA E CIDADANIA - UFG/UFRJ, 1., Goiânia, 2013.

SODRÉ, Muniz. Objeto da comunicação é a vinculação social. PCLA, São Paulo, v. 3, n. 1, out./nov./dez. 2001. Disponível em: <http://www2.metodista.br/unesco/PCLA/ revista9/entrevista\%209-1.htm>. Acesso em: 18 abr. 2013.

PERUZZO, Cicilia Krohling. Comunicação nos movimentos populares: a participação na construção da cidadania. Petrópolis, RJ: Vozes, 1998.

TEMER, Ana Carolina Rocha Pessoa; NERY, Vanda Cunha Albieri. Para entender as teorias da comunicação. Uberlândia: Asppectus, 2004. 